\title{
Increased Activity of the Respiratory Burst in Cord Blood Neutrophils: Kinetics of the NADPH Oxidase Enzyme System in Subcellular Fractions
}

\author{
DANIEL R. AMBRUSO, LINDA C. STORK, BRUCE E. GIBSON; AND GAIL W. THURMAN
}

Section of Hematology-Oncology, Department of Pediatrics, University of Colorado School of Medicine, and the Belle Bonfils Memorial Blood Center, Denver, Colorado 80262

\begin{abstract}
Previous studies with neutrophils from newborn infants compared to neutrophils from healthy adults have documented increased respiratory burst activity including enhanced superoxide anion $\left(\mathrm{O}_{2}^{-}\right)$production, nitroblue tetrazoleum dye reduction, and hexose monophosphate shunt activity. To investigate the biochemical basis for these observations, we examined oxidative metabolism in membrane-rich fractions of neutrophils. Neutrophils from cord blood of vaginally delivered term infants or healthy adults were disrupted by nitrogen cavitation and subcellular fractions collected on discontinuous sucrose density gradients. Subcellular fractions of newborn neutrophils separated in a fashion identical with samples from healthy adults. Activity of alkaline phosphatase, a plasma membrane marker, was increased 4- to 5-fold in disrupted cells free from nuclei (postnuclear supernatant) as well as plasma membrane fractions from newborn samples compared to those from healthy adults. Content of lactoferrin, a specific granule marker, was decreased in postnuclear supernatants but equivalent in specific granule fractions of newborn cells compared to those from adults. No differences were noted in myeloperoxidase content of postnuclear supernatants or any other subcellular fraction. Plasma
\end{abstract} membrane fractions from phorbol myristate acetate-stimulated cord blood neutrophils made significantly more $\mathrm{O}_{2}^{-}$ than samples from adults (newborn $32.9 \pm 8.1 \mathrm{nmol} \mathrm{O}_{2}{ }^{-}$/ $\mathrm{min} / \mathrm{mg}$ protein mean $\pm \mathrm{SEM}, n=3$ versus adult $10.8 \pm$ $4.2, n=3 ; p<0.05$ ). Plasma membrane-rich fractions were also collected by the technique of differential centrifugation and kinetic parameters of the NADPH-dependent oxidase enzyme(s) were measured for vaginally delivered newborn and adult samples. The $K_{m}{ }^{\text {app }}$ for NADPH for newborn fractions was significantly increased compared with adult samples (newborn $66 \pm 10 \mu \mathrm{M}, n=6$ versus adult $30 \pm 6, n=6 ; p<0.025$ ) but not to the extent that would be associated with abnormal cell function. In contrast, $V_{\max }$ of newborn membrane-rich fractions was 1.7 times that of adult samples (newborn $30.6 \pm 27 \mathrm{nmol} \mathrm{O}_{2}^{-}$/ $\mathrm{min} / \mathrm{mg}$ protein, $n=6$ versus adult $18.0 \pm 4.0, n=6 ; p<$ 0.025). Plasma membrane-rich fractions from term infants delivered by cesarean section without labor had a $\mathrm{K}_{\mathrm{m}}{ }^{\text {app }}$ of $67 \pm 20 \mu M, n=5$ which was different from adult samples $(p<0.05)$ and a $V_{\max }$ for $\mathrm{O}_{2}^{-}$production of $14.8 \pm 4.5$ which was less than that measured from samples from vaginally delivered infants $(p<0.01)$. The $K_{m}^{\text {app }}$ results

Received May 19. 1986: accepted October 9. 1986

Address correspondence and reprint requests to Daniel R. Ambruso, M.D. Department of Pediatrics. University of Colorado School of Medicine, 4200 East Ninth Avenue (C-220). Denver, CO 80262.

These studies were supported by Grant AI-19423 from the National Institutes of Health, the Belle Bonfils Memorial Blood Center, and the Stacy Marie True Memorial Fund. imply a qualitative difference in the fetal oxidase enzyme system. In addition, the increased $\mathrm{O}_{2}^{-}$production and $\mathrm{V}_{\text {max }}$ demonstrated in samples from vaginally delivered infants as compared to infants delivered by cesarean section or healthy adults suggests an effect of parturition on the fetal neutrophil which is similar to the effect of certain compounds such as lipopolysaccharide. The increased catalytic activity of the NADPH oxidase enzyme system in neutrophils from newborns may reflect "priming" during parturition. (Pediatr Res 21: 205-210, 1987)

\section{Abbreviations}

$\mathrm{O}_{2}^{-}$, superoxide anion

PMA, phorbol myristate acetate

.OH, hydroxyl radical

KRPD, Krebs Ringer phosphate buffer

psi, pounds per square inch

MPO, myeloperoxidase

Initiation of the respiratory burst is an important component of the microbicidal activity of the neutrophil and is crucial to the body's defense against infection. Diminished microbicidal activity by neutrophils from newborn infants, particularly stressed neonates, has been documented (1-3). Our previous studies demonstrated that neutrophils from newborn infants generate relatively less $\cdot \mathrm{OH}$, a particularly toxic oxygen metabolite important to the oxygen-dependent microbicidal activity of the neutrophil (4). The decreased production of $\cdot \mathrm{OH}$ was explained by diminished content of lactoferrin in newborn neutrophils (5). This protein is found in the specific granules of neutrophils and, when saturated with iron, enhances the production of . OH (6). While . OH production in newborn neutrophils is decreased, activity of the respiratory burst is increased in normal infants and may be decreased in stressed infants $(4,5,7-10,11)$. Understanding the biochemical basis for these differences in the respiratory burst is important in defining the microbicidal defect in newborn cells and the reasons for the newborn's risk for infection. In the following study, we evaluated the production of $\mathrm{O}_{2}{ }^{-}$and the kinetic parameters of the oxidase enzyme system in membrane-rich subcellular fractions of neutrophils from newborn infants.

\section{MATERIALS AND METHODS}

Reagents. The following reagents were purchased commercially: superoxide dismutase, cytochrome c, Micrococcus lysodeiketicus, $o$-dianisidine, Triton X-100, and E-toxate No. 210 
(Sigma Chemical Company, St. Louis, MO); PMA (Consolidated Midland Corporation, Brewster, NY); and IgG fraction of rabbit anti-human lactoferrin (U.S. Biochemical Corporation, Cleveland, $\mathrm{OH})$. Endotoxin-free reagents were obtained as follows: $\mathrm{NaCl}(14.6 \%)$, dextrose $(50 \%)$ (Abbott Laboratories, Chicago, IL); $\mathrm{KCl}(15 \%), \mathrm{MgSO}_{4} .7 \mathrm{H}_{2} \mathrm{O}(50 \%), \mathrm{CaCl}_{2}$ (10\%) (Invernex, Chagrin Falls, OH); EDTA, sodium cyanide, and sodium mono and dibasic phosphate (J. T. Baker, Phillipsburg, NJ); and Macrodex $6 \%$ in normal saline (Pharmicia Laboratories, Piscataway, $\mathrm{NJ})$. Stock solutions were made to the appropriate concentrations from these reagents with water determined to be free of endotoxin by the Limulus lysate assay (Sigma Chemical Company). All buffers and solutions used during isolation, stimulation, and disruption of neutrophils were determined to be endotoxin free by this method.

Isolation of neutrophils. Cord blood was obtained from placentas immediately after delivery and anticoagulated with 5-10 U/ $\mathrm{ml}$ heparin. For control studies, blood samples were taken from healthy adults in the same way. Informed consent was obtained in accordance with the requirements of the Human Subjects Committee of the University of Colorado Health Sciences Center. Infants delivered vaginally were products of full-term, uncomplicated pregnancies, labors, and deliveries; and no general anesthesia or intravenous analgesia administered to the mothers. As a separate control, samples were processed from placentas of five infants delivered by cesarean section. All of these infants were products of uncomplicated term pregnancies. None of the mothers was in labor prior to or during cesarean section and all deliveries were performed under spinal anesthesia. No perinatal complications occurred in any of the babies studied and all had Apgar score at 1 and $5 \mathrm{~min}$ of $\geq 8$.

Separation of neutrophils in endotoxin-free reagents were performed by a modification of previous described techniques (5). Whole blood was placed in plastic conical tubes and centrifuged at $600 \times g$ for $10 \mathrm{~min}$. After removing the plasma, a volume 2.5 times the original whole blood volume of Macrodex diluted 1.5;1 with normal saline was added to the cells. The mixture was inverted several times and allowed to sediment at room temperature for $1 \mathrm{~h}$. The supernatant was removed, centrifuged at 600 $\times g$ for $10 \mathrm{~min}$ and the red cells were lysed by hypotonic lysis. After washing three times with KRPD with glucose, $\mathrm{pH} 7.34$, the cells were resuspended to $5 \times 10^{7}$ cells $/ \mathrm{ml}$. Neutrophils obtained with this technique were $85-95 \%$ pure and $>99 \%$ viable as determined by exclusion of trypan blue.

Stimulation of neutrophils. Neutrophils in KRPD were preincubated at $37^{\circ} \mathrm{C}$ for $4 \mathrm{~min}$ in the presence of $1.0 \mathrm{mM} \mathrm{KCN}$, and then were stimulated by the addition of $100 \mathrm{ng} / \mathrm{ml} \mathrm{PMA.} \mathrm{After}$ incubation for $3 \mathrm{~min}$ at $37^{\circ} \mathrm{C}$, an equal volume of cold disruption buffer (same as KRPD except calcium was deleted and $\mathrm{MgSO}_{4}$ was present at $2.5 \mathrm{mM}$ ) was added to the cells and the mixture was centrifuged at $800 \times g$ for $8 \mathrm{~min}$. The pelleted cells were then resuspended in disruption buffer.

Disruption of neutrophils. Neutrophils in disruption buffer were placed in a small Falcon tube with a magnetic stir bar and subjected to nitrogen cavitation in a Parr cell disruption bomb (4635, Parr Instrument Company, Moline, IL) as previously described by Klempner et al. (12). The exact conditions were somewhat different than originally described. After flushing for $5 \mathrm{~min}$ with nitrogen gas, the exhaust port of the bomb was closed, allowing the pressure to increase to the desired level. This pressure was maintained for $20 \mathrm{~min}$ at $4^{\circ} \mathrm{C}$. The exhaust port was then opened and the cavitate collected dropwise from the port into an equal volume of buffer containing $0.34 \mathrm{M}$ sucrose (wt/ $w t)$ and $2.5 \mathrm{mM}$ EDTA. In a series of experiments to determine the optimal pressure for disruption, breakage of granules was monitored by measuring lysozyme (13) in the supernatant following centrifugation of the cavitate at $27,000 \times g$; cell disruption was determined by cell counts before and after cavitation; and breakage of nuclei was documented by comparing hemocytometer cell counts before disruption with nuclei counts after disrup- tion. At pressures greater than $250 \mathrm{psi}$, there was evidence of significant breakage of granules (30-40\% of total lysozyme activity in the $27,000 \times g$ supernatant). The extent of cell breakage was dependent on cavitation pressure, $50 \%$ cell disruption at $75-$ $150 \mathrm{psi}, 80 \%$ at $200-300 \mathrm{psi}$, and $>90 \%$ at pressures $>300$ psi. Significant nuclear disruption was not seen at pressures $<300$ psi. A pressure of $225-250$ psi minimized the nuclear and granule breakage and maximized the cell disruption. In all subsequent experiments, disruption was carried out under these conditions and the cavitate was centrifuged at $800 \times g$ for $10 \mathrm{~min}$ to remove nuclear debris and unbroken cells, yielding the "postnuclear supernatant."

Separation of subcellular fractions. Separation of subcellular fractions from resting and PMA-stimulated cells disrupted by nitrogen cavitation was performed by two different techniques. In the first technique, discontinuous sucrose density gradients were used. The postnuclear supernatant of the cavitate was layered over a gradient consisting of 1.5-2.0 ml layers of 18,28 , 33 , and $42 \%$ sucrose $(\mathrm{w} / \mathrm{w})$ on a $2.0 \mathrm{ml}$ cushion of $50 \%$ sucrose. These gradients were centrifuged at $100,000 \times g$ for $2 \mathrm{~h}$ in a Beckman L5-50 ultracentrifuge equipped with swinging bucket rotor (SW-41), and fractions were removed by hand or with a gradient unloader. Alternatively, the postnuclear supernatant was transferred to Corex tubes and centrifuged in a Beckman J-21B high-speed centrifuge with a JA-20 rotor at $9500 \times g$ for $15 \mathrm{~min}$. The pellet was resuspended in $0.34 \mathrm{M}$ sucrose and stored at $-70^{\circ}$ $\mathrm{C}$ for further studies. The supernatant was centrifuged at 32,000 $\times g$ for $45 \mathrm{~min}$, and the resultant pellet was resuspended in 0.34 $\mathrm{M}$ sucrose and was also stored at $70^{\circ} \mathrm{C}$.

Enzyme assays and superoxide anion production. The activities of MPO and alkaline phosphatase were measured by the oxidation of $o$-dianisidine and the reaction with $p$-nitrophenyl phosphate respectively $(5,13)$. Lactoferrin was quantitated by rocket immunoelectrophoresis (5), and total protein was measured by the method of Lowry et al. (14). Production of $\mathrm{O}_{2}^{-}$was measured as superoxide dismutase-inhibitable reduction of ferricytochrome $\mathrm{c}$ in a dual beam recording spectrophotometer (Carry 118) as previously described (15). The reaction mixture contained $0.08 \mathrm{mM}$ ferricytochrome $\mathrm{c}, 25 \mu \mathrm{l}$ of membrane-rich fraction, and the appropriate concentration of NADPH in a total volume of $300 \mu \mathrm{l}$. The reference cuvette contained all of the above plus $10 \mu \mathrm{g}$ of superoxide dismutase. The exact concentration of NADPH was determined by measurement of the absorbance of $340 \mathrm{~nm}$ and calculation using the millimolar extinction coefficient $\left(6.2 \mathrm{mM}^{-1} \mathrm{~cm}^{-1}\right.$ (16). Quantitation was carried out using the extinction coefficient $2.1 \times 10 \mathrm{M}^{-1} \mathrm{~cm}^{-1}$ for reduced versus oxidized cytochrome $\mathrm{c}$ and the results were expressed as $\mathrm{nmol} \mathrm{O}-\overline{2}$ produced/mg protein/minute. In kinetic studies of the oxidase enzyme(s), superoxide anion production at concentrations of NADPH ranging from 0.01 to $0.25 \mathrm{mM}$ was measured, and the data analyzed using Lineweaver-Burke plots. The kinetic parameters were calculated using the statistical methods of Wilkinson (17).

\section{RESULTS}

Separation of subcellular fractions. The results of separation of subcellular fractions from unstimulated neutrophils on discontinuous sucrose density gradients are summarized in Table 1. The plasma membrane marker, alkaline phosphatase, was found in highest specific activity in the 18 and $28 \%$ bands accounting for a 19- to 29-fold increase in specific activity over that found in the postnuclear supernatant. Of interest is the increased activity of alkaline phosphatase demonstrated in neutrophils (newborn $2.7 \pm 0.3 \mathrm{mU} / 10^{7}$ cells, mean $\pm \mathrm{SEM}, n=4$; adult $0.7 \pm$ $0.6, n=8$ ) and in all subcellular fractions of cord blood neutrophils from vaginally delivered infants. The highest content of the specific granule marker, lactoferrin, was seen in the 33 and $38 \%$ fractions. No differences between adult and cord blood fractions were seen except for a significantly decreased amount of lacto- 
Table 1. Separation of subcellular fractions from unstimulated neutrophils on discontinuous sucrose density gradients*

\begin{tabular}{|c|c|c|c|c|c|c|}
\hline \multirow[b]{3}{*}{ Fraction } & \multicolumn{6}{|c|}{ Specific activity of marker proteins } \\
\hline & \multicolumn{2}{|c|}{ Alkaline phosphatase $\dagger$} & \multicolumn{2}{|c|}{ Lactoferrin $\dagger$} & \multicolumn{2}{|c|}{ Myeloperoxidase $\dagger$} \\
\hline & Adult & Cord & Adult & Cord & Adult & Cord \\
\hline Postnuclear Supernatant & $3.3 \pm 0.6 \ddagger$ & $20.3 \pm 4.0 \S$ & $56.0 \pm 5.1$ & $19.6 \pm 4.0 \|$ & $4.9 \pm 2.1$ & $8.8 \pm 4.8$ \\
\hline $18 \%$ & $57.1 \pm 28.4$ & $342.4 \pm 62.7 \S$ & $19.5 \pm 7.1$ & $42.7 \pm 3.7$ & $10.4 \pm 3.5$ & $39.6 \pm 14.0$ \\
\hline $28 \%$ (membrane) & $89.7 \pm 25.9$ & $460.7 \pm 46.3 \|$ & $49.9 \pm 6.0$ & $62.7 \pm 15.3$ & $47.2 \pm 14.0$ & $39.3 \pm 5.9$ \\
\hline $33 \%$ (specific) & $7.6 \pm 5.1$ & $95.2 \pm 4.2 \|$ & $289.6 \pm 29.5$ & $278.3 \pm 77.2$ & $46.6 \pm 6.0$ & $73.2 \pm 19.4$ \\
\hline $38 \%$ & $3.1 \pm 0.5$ & $29.5 \pm 4.1 \|$ & $201.6 \pm 65.3$ & $132.6 \pm 5.1$ & $124.6 \pm 39.0$ & $190.3 \pm 24.2$ \\
\hline $42 \%$ (azurophilic) & $3.6 \pm 2.9$ & $23.9 \pm 6.8$ & $58.3 \pm 18.7$ & $60.1 \pm 15.0$ & $114.2 \pm 22.4$ & $126.4 \pm 44.5$ \\
\hline
\end{tabular}

* Isolation and disruption of neutrophils and separation of subcellular fractions on discontinuous sucrose density gradients as described in "Materials and Methods."

† Assays for marker proteins measured by reaction with $p$-nitrophenyl phosphate (alkaline phosphatase) rocket immunoelectrophoresis (lactoferrin), and oxidation of o-dianisidine. Results are specific activity, expressed as $\Delta \mathrm{A} / \mathrm{mg}$ protein $\times 10^{-3}$, for alkaline phosphatase and myeloperoxidase or ratio of lactoferrin to total protein $(\mu \mathrm{g} / \mathrm{mg}$ protein).

$\$$ Numbers represent mean \pm SEM of gradients performed on three cord blood and adult control samples.

$\S$ Significant difference between cord blood and adult samples, $p<0.01$ by unpaired $t$ test.

$\|$ Significant difference between cord blood and adult samples, $p<0.005$ by unpaired $t$ test.

ferrin in the postnuclear supernatant of cord cells $(p<0.005)$. The highest amount of MPO activity was found in the 38 and $42 \%$ bands, and no differences between adult and newborn samples were noted. Insignificant amounts of protein markers were found in the $50 \%$ cushion (data not shown). In accordance with the location of the marker proteins, the membrane appeared to be located in the $28 \%$ band, the specific granules in the $33 \%$ band, and the azurophilic granules in the $42 \%$ band. Although there were quantitative differences in marker proteins, subcellular fractions from cord blood neutrophils appeared to separate on the discontinuous gradients in a fashion qualitatively identical to fractions from neutrophils of adult controls.

$\mathrm{O}_{2}^{-}$production by membrane fractions. In subsequent experiments, cells were stimulated with PMA; subcellular fractions were prepared on density gradients; and the membranes $(28 \%$ band) were collected. $\mathrm{O}_{2}^{-}$production was measured in the presence of $0.1 \mathrm{mM}$ NADPH. Membranes from cord blood neutrophils of vaginally delivered infants produced three times as much $\mathrm{O}_{2}^{-}$as membranes from control neutrophils (adult 10.8 \pm 4.2 $\mathrm{nmol} \mathrm{O}-1 \mathrm{~min} / \mathrm{mg}$ protein, mean $\pm \mathrm{SEM}, n=3$; newborn 32.9 $\pm 8.1, n=3 ; p<0.05$ by unpaired $t$ test).

Because of the sucrose gradient procedure produced insufficient quantity of membrane fraction, kinetic analysis of NADPH oxidase was performed with membrane-rich fractions prepared by differential centrifugation. Membrane fractions prepared by this technique have previously been shown to contain at least $75 \%$ of the NADPH-dependent oxidase activity (18). Rates of $\mathrm{O}_{2}^{-}$production by membrane fractions prepared by differential centrifugation were measured at concentrations of NADPH between 0.01 and $0.25 \mathrm{mM}$ for six adult and six vaginally delivered infant specimens. Plots of velocity versus substrate concentration revealed a hyperbolic saturation curve for all samples. Figure 1 presents double reciprocol plots for $\mathrm{O}_{2}^{-}$production versus substrate (NADPH) concentration for representative sample neutrophil membrane fraction from adult control and cord blood. Data from all newborn samples analyzed in this way exhibited the same pattern, decreased slopes, and y-intercepts compared to adult samples. The kinetic parameters for oxidase activity for these samples are summarized in Table 2 . The membrane fraction of cells from vaginally delivered babies exhibited a significantly increased $\mathrm{K}_{\mathrm{m}}$ app for NADPH compared to adult samples $(p<0.025)$. However, this was not out of the range of normal values published by other investigators $(19-21)$. The $V_{\max }$ for cord blood samples was 1.7 times greater than values for adult cells $(p<0.025)$. Also included in Table 2 is the calculated rate of $\mathrm{O}_{2}^{-}$production by subcellular fractions based on measured kinetic parameters and an estimated intracellular concentration of NADPH of $90 \mu \mathrm{M}$. This estimation of NADPH concentration

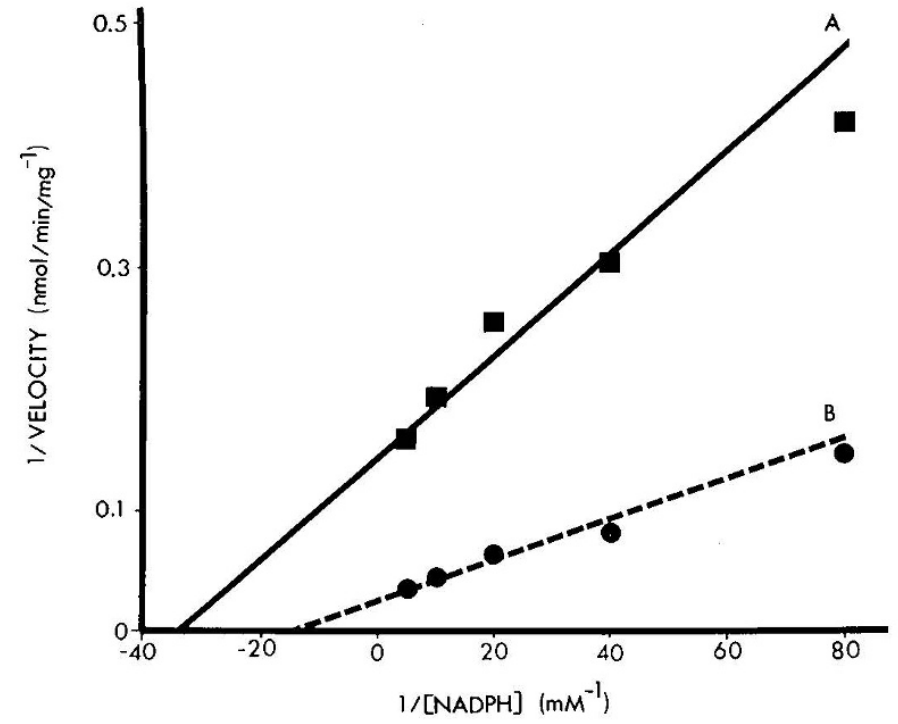

Fig. 1. NADPH-dependent $\mathrm{O}_{2}^{-}$production by membrane-rich fractions harvested by discontinuous centrifugation. Data presented as plot of $\mathrm{O}_{2}^{-}$production versus substrate concentration by double reciprocol Lineweaver-Burk analysis. $A$, membrane fraction from neutrophils of adult controls; $B$, cord blood.

in neutrophils was made with data from previous studies documenting content of NADPH to be $2.4 \mathrm{nmol} / 10^{8}$ cells (22) and estimates of average neutrophil size. At physiologic concentrations of NADPH, the rate of $\mathrm{O}_{2}^{-}$production was calculated to be $30 \%$ greater in newborn compared to adult membrane samples, a value which is comparable to results reported in whole cells $(5)$.

To determine the role of labor in the differences in kinetic parameters of the oxidase enzyme system, blood samples from placentas of five infants delivered by cesarean section under spinal anesthesia without preceding labor were obtained and membrane-rich fractions were prepared by differential centrifugation. As with adult and vaginally delivered term infants, membrane-rich fractions from babies delivered by cesarean section demonstrated a hyperbolic curve when $\mathrm{O}_{2}^{-}$production was plotted against substrate concentration. The kinetic parameters for this group of babies were $\mathrm{K}_{\mathrm{m}}^{\text {app }}, 67 \pm 20 \mu \mathrm{M}, n=5$, and $\mathrm{V}_{\max }$ $14.8 \pm 4.5 \mathrm{nmol} / \mathrm{min} / \mathrm{mg}$ protein. The $\mathrm{K}_{\mathrm{m}}{ }^{\text {app }}$ for babies delivered by cesarean section was identical to that of vaginally delivered infants but higher than that from adults $(p<0.05)$. $\mathrm{V}_{\max }$ for the 
Table 2. Kinetic parameters for $\mathrm{O}_{2}^{-}$generation by membrane fractions of neutrophils*

\begin{tabular}{cccc}
\hline $\begin{array}{c}\text { Membrane } \\
\text { source }\end{array}$ & $\begin{array}{c}\mathrm{K}_{\mathrm{m}}^{\text {app }} \\
(\mu \mathrm{M} \mathrm{NADPH})\end{array}$ & $\begin{array}{c}\mathrm{V}_{\max } \\
(\mathrm{nmol} \mathrm{O} / \mathrm{min} / \mathrm{mg} \text { protein })\end{array}$ & $\begin{array}{c}\text { Calculated velocity } \\
\left(\mathrm{nmol} \mathrm{O} \mathrm{O}_{2}^{-} / \mathrm{min} / \mathrm{mg}\right)\end{array}$ \\
\hline Adult & $30 \pm 6 \ddagger$ & $18.0 \pm 4.0$ & 13.5 \\
Cord & $66 \pm 10 \S$ & $30.6 \pm 2.7 \S$ & 17.6 \\
\hline
\end{tabular}

* Membrane-rich fractions of PMA-stimulated neutrophils harvested after disruption by nitrogen cavitation and separation by differential centrifugation as described in "Materials and methods."

† Velocity calculated using concentrations of intracellular NADPH of $90 \mu \mathrm{M}$ (see "Results"), mean values for $\mathrm{K}_{\mathrm{m}}^{\text {app }}$ and $\mathrm{V}_{\max }$ above, and the hyperbolic equation:

$$
\mathrm{v}=\mathrm{V}_{\max } \cdot[\mathrm{NADPH}] / \mathrm{K}_{\mathrm{m}}+[\mathrm{NADPH}]
$$

$\$$ Numbers represent mean \pm SEM of results from six separate cord blood and adult samples.

$\S$ Valucs for cord blood samples significantly different from adult samples, $p<0.025$ by unpaired $t$ test.

cesarean section infants was identical to adults but less than vaginally delivered infants $(p<0.01)$.

\section{DISCUSSION}

In recent years, many studies have addressed the adequacy of phagocyte function in the newborn infant. Defective neutrophil microbicidal activity has been documented especially at high bacteria-to-neutrophil ratios (1-3). Associated with the killing defect are abnormalities in oxidative metabolism including increased nitroblue tetrazolium dye reduction, increased stimulated hexose monophosphate shunt activity, and enhanced production of $\mathrm{O}_{2}^{-}(4,7,8,10)$. In addition, the rate of $\mathrm{O}_{2}^{-}$ production by cord blood neutrophils was increased compared to neutrophils from adults (11). While the respiratory burst is quantitatively increased in newborn neutrophils, chemiluminescence, a phenomenon that reflects interaction of a variety of free radicals with cellular excitable substrates (18), is decreased (23, 24). We have shown that despite normal-to-increased production of $\mathrm{O}_{2}^{-}$, generation of. $\mathrm{OH}$ is relatively decreased in cord blood neutrophils $(4,5)$. This diminished $\cdot \mathrm{OH}$ production was associated with normal degranulation of specific and azurophilic granules but diminished content of lactoferrin in neutrophils from newborns compared to adult controls. Lactoferrin is an ironbinding protein which has been shown to increase production of . OH in whole cells as well as cell-free systems (6). Although the diminished content of lactoferrin could account for the decreased . OH generation by neutrophils from newborns, the reason for the increased $\mathrm{O}_{2}^{-}$production and associated measurements of the initiation of the respiratory burst is not well understood. These abnormalities in the respiratory burst appear to be limited to neutrophils since there are no great differences in production of . $\mathrm{OH}$ and/or $\mathrm{O}_{2}^{-}$by monocytes or monocyte-derived macrophages from cord blood compared to those from healthy adults (25). In the current study we attempted to examine the kinetics of the oxidase enzyme system to further delineate the basis for the increased $\mathrm{O}_{2}^{-}$production in neutrophils from newborn infants.

In our initial experiments, cells were isolated with endotoxinfree reagents to avoid additional priming of the oxidase demonstrated by Guthrie et al. (26). Membrane-rich fractions were separated from other subcellular components by centrifugation on discontinuous sucrose density gradients. Subcellular fractions from unstimulated cord blood neutrophils from vaginally delivered term infants separated in a manner identical to subcellular fractions of neutrophils from adult blood. However, two differences documented in the analysis of newborn and adult samples merit further discussion. First, the 4- to 5-fold increase in alkaline phosphatase activity measured in the postnuclear supernatants as well as the various subcellular fractions from neonatal samples confirms previous histochemical studies (27). The reason for difference in alkaline phosphatase activity in cord blood neutrophils is not known. We have recently demonstrated that during purification of alkaline phosphatase from neutrophils by butanol extraction and concanavalin A affinity chromatography, activity of this enzyme in cord blood samples remains 3- to 4-fold increased compared to the enzyme isolated from adult cells at every step of the purification (28). The increased alkaline phosphatase activity was documented for samples obtained from infants delivered vaginally or those delivered by cesarean section without labor, indicating that changes during parturition were not responsible for the differences noted. In addition, there were no differences in temperature stability at 56 and $65^{\circ} \mathrm{C}$ for all sources of the enzyme. Furthermore, enzyme from both newborn and adult neutrophils exhibited a pattern of inhibition with standard inhibitors identical to liver/bone/kidney alkaline phosphatase and distinct from intestinal or placental alkaline phosphatase. These results taken together with those from the density gradients performed in this study suggest that the increase in alkaline phosphatase in newborn neutrophils may be related to increased specific activity of the enzyme rather than increased content of the enzyme in neutrophils. Determination as to whether this represents a fetal enzyme or stimulation of alkaline phosphatase during pregnancy awaits further evaluation.

Second, the decrease in content of lactoferrin in postnuclear supernatants of neutrophils from newborns confirms our previous studies in whole cells (5). The question still remains, however, whether this decrease in content is a result of decreased numbers of specific granules because of degranulation or a decreased content of lactoferrin within the granules themselves because of diminished production of the protein. In our previous study, we showed that there was a small decrease in specific granules in cord blood neutrophils by electron microscopy. However, this could not completely account for a $50 \%$ decrease in cellular content of lactoferrin. The results of the current study demonstrating equivalent content of lactoferrin per $\mathrm{mg}$ total protein of the specific granule fraction of newborn neutrophils compared to adult samples suggest that specific granule fractions from neonatal cells contain normal amounts of lactoferrin and support degranulation of specific granules rather than diminished production of the protein as the cause for diminished whole cell levels of lactoferrin.

Production of $\mathrm{O}_{2}^{-}$by membrane fraction of PMA-stimulated neutrophils from vaginally delivered newborns was increased, a finding that is consistent with measurements of $\mathrm{O}_{2}^{-}$production in whole cells. Because of the limitations in the amount of cord blood that could be obtained from placentas and hence, neutrophils, limited quantities of membrane could be harvested; $\mathrm{O}_{2}^{-}$ production could be performed at only one concentration of NADPH. With a second technique employing differential centrifugation for isolating membrane-rich fractions, sufficient quantities of membrane were recovered to complete the kinetic analysis of $\mathrm{O}_{2}^{-}$production (18). Examination of newborn neutrophil membrane-rich fragments demonstrated differences in both $\mathrm{K}_{\mathrm{m}}$ app as well as $\mathrm{V}_{\max }$ compared to samples from healthy adult controls. The $\mathrm{K}_{\mathrm{m}}$ values for cord cells of vaginally delivered term 
infants were higher than for adult samples suggesting the possibility of a qualitative difference in the fetal oxidase enzyme(s). However, the actual values for both adult and newborn were within the range published by other investigators for normal neutrophils $(15,16,18-21,26,29,30)$ and were not at a level which would be associated with abnormal cell function $(29,30)$. Values for $\mathrm{V}_{\max }$ in membrane-rich fractions from newborn neutrophils was nearly twice that for the samples from normal adults. A high $\mathrm{V}_{\max }$ for $\mathrm{O}_{2}^{-}$production could explain the increased $\mathrm{O}_{2}^{-}$ production in whole neutrophils $(4,5,10)$.

Evaluation of kinetic parameters of the oxidase enzyme system in membrane fractions from infants delivered by cesarean section without labor was completed to help define the effects of parturition on fetal neutrophils. The $\mathrm{K}_{\mathrm{m}}{ }^{\mathrm{app}}$ for NADPH of fractions from these infants was significantly higher than adult controls, further confirming a qualitative difference in the fetal oxidase enzyme system. Furthermore, $\mathrm{V}_{\max }$ of samples from cesarean delivered infants was similar to adult samples and lower than that measured for vaginally delivered infants. This suggests that the increased activity in the respiratory burst in neutrophils from newborns is related to changes that occur during parturition.

Several implications of these data warrant further consideration. First, since $\mathrm{K}_{\mathrm{m}}{ }^{\text {app }}$ for the oxidase in newborn cells was increased, the question arises as to whether there is sufficient NADPH in the cell to saturate the oxidase in newborns. Should NADPH be at levels less than the $K_{m}{ }^{\text {app }}$ for the newborn, the newborn oxidase would run more slowly than adult oxidase. Based on previous measurements (see "Results"), the concentration of NADPH in the cell is estimated to be $90 \mu \mathrm{M}$, a concentration sufficient to saturate both newborn and adult oxidase. With an estimate of the concentration of NADPH and measurement of $\mathrm{V}_{\max }$, calculation of the velocity of the oxidase from vaginally delivered babies and adult controls can be completed. Results of these calculations for our experimental data were presented in Table 2; the oxidase enzyme system in newborn cells from vaginally delivered infants should generate $\mathrm{O}_{2}^{-}$at a rate $30 \%$ greater than adult cells. This is consistent with measurement of $\mathrm{O}_{2}^{-}$generation in intact neutrophils from newborns $(4,5)$. While a higher $K_{m}$ for NADPH in newborn samples implies a fetal form of the oxidase enzyme(s), the mechanism by which $\mathrm{V}_{\max }$ is increased in vaginally delivered infants remains to be defined.

Recent studies link granule constituents with the respiratory burst. Evidence for the role of MPO in terminating the respiratory burst has been presented (31). Furthermore, activation of the respiratory burst may require translocation of cytochrome $b$ and other constituents from specific granules to plasma membrane (32). The data presented herein as well as in our previous study showed that neutrophils from term vaginally delivered infants have equivalent activity of MPO compared to cells from healthy adults, eliminating altered MPO activity as a reason for increased $\mathrm{O}_{2}^{-}$production. However, we have demonstrated decreased numbers of specific granules and their contents in neutrophils from newborn infants (5). The importance of specific granule components to the respiratory burst, our previous studies demonstrating loss of specific granules and/or their contents, and our current measurement of higher $V_{\max }$ of the oxidase enzyme system in term, vaginally delivered infants compared to infants delivered by cesarean section without labor and healthy adults suggest that degranulation of neutrophils during parturition may result in assembly of the components of the respiratory burst and priming of the oxidase enzyme(s). This effect would account for the increased $\mathrm{O}_{2}^{-}$production in whole neutrophils from newborns and would appear similar to the action of endotoxin on the respiratory burst of neutrophils in vitro demonstrated by Guthrie et al. (26). Further investigations are necessary to explore the respiratory burst in newborn neutrophils and to define those characteristics which are related to a fetal form of the oxidase enzyme system. However, the current studies suggest that the increased activity of the NADPH oxidase enzyme system in neutrophils from newborn infants reflects "priming" during parturition.

Acknowledgments. The authors thank Kathy Hoyer for help in preparation of this manuscript and Drs. Richard B. Johnston, Jr. and Michael Pabst for their constructive suggestions.

\section{REFERENCES}

1. Coen R, Grush O, Kauder C 1969 Studies of bacterial activity and metabolism of the leukocyte in full-term neonates. J Pediatr 75:400-406

2. Stoerner JW. Pickering LK, Adcock EW, Morriss FH Jr 1978 Polymorphonuclear leukocyte function in newborn infants. J Pediatr 93:862-864

3. Wright WC Jr, Ank BJ, Herbert J, Stiehm R 1975 Decreased bactericidal activity of leukocytes of stressed newborn infants. Pediatrics 56:579-584

4. Ambruso DR. Altenburger K. Johnston RB Jr 1979 Defective oxidative metabolism in newborn neutrophils: discrepancy between superoxide anion and hydroxyl radical generation. Pediatrics 64(suppl):722-725

5. Ambruso DR, Bentwood B, Henson PM, Johnston RB Jr 1984 Oxidative metabolism of cord blood neutrophils: relationship to content and degranulation of cytoplasmic granules. Pediatr Res 18:1148-1153

6. Ambruso DR. Johnston RB Jr 1981 Lactoferrin enhances hydroxyl radical production by human neutrophils, neutrophil particulate fractions and an enzymatic generating system. J Clin Invest 67:352-360

7. Anderson DC, Pickering LK, Feigin RD 1974 Leukocyte function in normal and infected nconates. J Pediatr 85:420-425

8. Park BH, Holmes B, Good RA 1970 Metabolic activities in leukocytes of newborn infants. J Pediatr 76:237-241

9. Mills EL. Thompson T. Bjorksten B, Quie PG 1979 The chemiluminescence response and bactericidal activity of polymorphonuclear neutrophils from newborns and their mothers. Pediatrics 63:429-434

10. Shigeoka AO. Charette RP. Wyman ML. Hill HR 1981 Defective oxidative metabolic responses of neutrophils from stressed infants. J Pediatr 98:392398

11. Strauss RG. Snyder EL 1983 Activation and activity of superoxide generating system of neutrophils from human infants. Pediatr Res 17:662-664

12. Klempner MS. Mikkelsen RB. Corfman DH, Andre-Schwartz J 1980 Neutrophil plasma membranes. I. High yield purification of human neutrophil plasma membrane vesicles by nitrogen cavitation and differential centrifugation. J Cell Biol 86:21-28

13. Ambruso DR. Sasada M, Nishiyama H. Kubo A. Komiyama A. Allen RH 1984 Studies of neutrophil function in a patient with specific granule deficiency. J Clin Immunol 4:23-30

14. Lowry OH, Rosebrough NJ, Farr AL, Randall RJ 195! Protein measurement with the Folin phenol reagent. J Biol Chem 193:265-275

15. McPhail LC. Henson PM. Johnston RB Jr 1981 Respiratory burst enzyme in human neutrophils. Evidence for multiple mechanisms of activation. J Clin Invest 67:710-716

16. Light DR, Walsh C, O'Callaghan AM, Goetzl EJ, Tauber Al 1981 Characteristics of co-factor requirements for the superoxide-generating NADPH oxidase of human polymorphonuclear leukocytes. Biochemistry J 20:14681476

17. Wilkinson GN 1961 Statistical estimates of enzyme kinetics. Biochem J 80:324-332

18. McPhail LC. Snyderman R 1983 Activation of the respiratory burst enzyme of human polymorphonuclear leukocytes by chemoattractants and other soluable stimulae: evidence that the same oxidase is activated by different transductional mechanisms. J Clin Invest 72:192-200

19. Seger RA. Tiefenauer L. Matsunaga T, Wildfeuer A, Newberger PE 1983 Chronic granulomatous disease due to granulocytes with abnormal NADPH oxidase activity and deficient cytochrome b. Blood 61:423-428

20. Gabig TG, Babior BM 1979 The $\mathrm{O}_{2}$-forming oxidase responsible for the respiratory burst in human neutrophils. Properties of the solubilized enzyme. J Biol Chem 254:9070-9074

21. Suzuki Y, Lehrer RI $1980 \mathrm{NAD}(\mathrm{P}) \mathrm{H}$ oxidase activity in human neutrophils stimulated by phorbol myristate acetate. J Clin Invest 66:1409-1418

22. Bachner RL, Johnston RB Jr. Nathan DG 1972 Comparative study of metabolic and biochemical characteristics of severely glucose-6-phosphate dehydrogenase-deficient polymorphonuclear leukocytes and leukocytes from children with chronic granulomatous disease. J Reticuloendothelial Soc 12:150166

23. Strauss RG. Siefert MJ 1978 Oxidative metabolism in cord-blood polymorphonuclear leukocytes. Arch Dis Child 53:78-81

24. Van Epps DE, Goodwin JS, Murphy S 1978 Age-dependent variations in polymorphonuclear leukocyte chemiluminescence. Infect Immun 22:57-61

25. Speer CP, Ambruso DR, Grimsley J, Johnston RB Jr 1985 Oxidative metabolism of cord blood monocytes and monocyte-derived macrophages. Infect Immun 50:919-921

26. Guthrie LA, McPhail LC, Henson PM, Johnston RB Jr 1984 Priming of neutrophils for enhanced release of oxygen metabolites by bacterial lipopolysaccharide. Evidence for increased activity of superoxide-producing enzyme. 
J Exp Med 160:1656-1671.

27. Sadovsky E. Matz D. Diamant YZ. Polishuk WZ 1975 Leukocyte alkaline phosphatase in the newborn. Biol Neonate 27:96-101

28. Ambruso DR. Bailey CM. Cusack NA. Stork LC 1986 Alkaline phosphatase in cord blood neutrophils: evidence for increased specific activity. Pediatr Res 20:387A (absir)

29. Lew PD. Southwick FS. Stossel TP. Whitin JC. Simons E, Cohen HJ 1981 A variant of chronic granulomatous disease: deficient oxidative metabolism duc to low affinity NADPH oxidase. N Engl J Med 305:1329-1333
30. Shurin SB, Cohen HJ, Whitin JC. Newburger PE 1983 Impaired granulocyte superoxide production and prolongation of the respiratory burst due to a low affinity NADPH-dependent oxidase. Blood 62:564-571

31. Jandle RC, Andre-Schwartz J, Borges-DuBois L, Kipnes RS, McMurrich J, Babior BM 1978 Termination of the respiratory burst in human neutrophils. $\mathrm{J}$ Clin Invest 61:1176-1185

32. Borregard N, Heiple JM, Simons ER, Clark RA 1983 Subcellular localization of the b-cytochrome component of the human neutrophil microbicidal oxidase translocation during activation. J Cell Biol 97:52-61 